\title{
An increased effect of pilocarpine on the pupil by application of the drug in oil
}

\author{
SHIRLEY A. SMITH, S. E. SMITH, AND R. LAZARE \\ From the Department of Pharmacology, St. Thomas's Hospital Medical School, London, and \\ Smith and Nephew Research Limited, Gilston Park, Harlow, Essex
}

SUMMARY In healthy volunteers pilocarpine in an oily solution had a greater degree and duration of effect on the pupil than the same amount of drug given in aqueous solution. Blue- and browneyed subjects had similar degrees of miosis, but the time taken to reach peak effects was longer with the latter. It can be concluded that eye drops made with an oily solvent may provide an improvement in the treatment of glaucoma with pilocarpine.

The routine use of aqueous pilocarpine eye drops for the treatment of glaucoma necessitates instillation at least 3 times daily for effective control of pressure because of the short duration of drug action. Patient compliance with such treatment regimens is poor (Vincent, 1971), and such failure is likely to contribute to inadequate pressure control and deterioration of vision.

Experimental studies indicate that dissolving drugs in oil leads to improved corneal penetration (Swan and White, 1942) and consequent prolonged drug effects (Norn, 1964; Borgmann and Wurster, 1973). In the present work pilocarpine was administered in identical amounts in oily and aqueous solutions to healthy volunteers to investigate whether the former increased the degree and duration of drug effect on the pupil. Electronic pupillography was employed so that the action of pilocarpine on both diameter and light reflex could be measured. Two groups of subjects were used, with blue or brown eyes, since the action of pilocarpine has been reported to differ according to the degree of iris pigmentation (Barbee and Smith, 1957; Harris and Galin, 1971).

\section{Methods}

Experiments were performed on 13 male and female subjects (17 to 21 years old) of whom 7 had brown and 6 had blue eyes. None smoked, took drugs, or had evidence of eye disease. Subjects were treated topically at intervals of at least a week with 1 drop of pllocarpine in an oily or aqueous vehicle. The former was a $2 \%$ concentration of the base in castor oil,

Address for reprints: Dr S. A. Smith, Deparıment of Pharmacology, St. Thollas's Hospital Medical School, London SEI 7EH prepared and sterilised by the pharmacy department of Smith and Nephew Research Ltd. With the Pasteur pipettes used to deliver the drug, 1 drop of this solution delivered $1.75 \times 10^{-6}$ moles of base. The concentration of the aqueous solution of pilocarpine nitrate $(1.53 \%)$ dissolved in $0.9 \%$ saline at $\mathrm{pH} 5.8$, was adjusted so that 1 drop delivered the same molar quantity of pilocarpine base as with the oily solution. Aqueous preparations were made up immediately before use.

Pupillary measurements were made with a Whittaker Corporation series 1800 binocular infrared television pupillometer (Lowenstein and Loewenfeld, 1958) before and at intervals of up to 24 hours after drug instillation. Three readings were obtained during the first 2 hours to determine peak effects. Measurements were performed in darkness, but the subjects were not dark-adapted at the time. Trains of 6 Maxwellian light stimuli of 0.5 s duration, focused in the plane of the pupil, were applied to the untreated eye and were far enough apart (10 s) to allow complete recovery between reflexes. The light intensity was about $8 \log$ units above the dark adaptation light threshold. The responses of the treated (right) and untreated (left) eyes were recorded, the second to sixth responses being averaged and the reflex amplitude and diameter at the foot of the averaged response recorded.

The findings were analysed statistically by analysis of variance for a $2 \times 2$ factorial experimental design (drug preparation and eye colour) using standard methods (Snedecor and Cochran, 1967).

\section{Results}

Fig. 1 illustrates the 2 actions of pilocarpine on the pupil that were measured in this study. In addition 
to the miosis, which was expressed as the difference in resting diameters between the treated and untreated eyes, there was a reduced reflex response to light, expressed as the lett-right difference in reflex amplitude as a percentage of that of the untreated left eye.

The time course of these effects of pilocarpine are shown in Fig. 2, from which it is apparent that the same amount of drug has far greater effects when given in an oily than in an aqueous solvent in both blue- and brown-eyed subjects. The effect of the oily preparation was so great that maximal degrees of miosis and total inhibition of the light reflex were usually obtained.

The magnitude and timing of peak drug effects are given in Table 1 and the influences of solvent and eye colour on these effects in Table 2. The slight discrepancies seen between these values and those indicated in Fig. 2 arise from the different methods of presentation. From the oily solvent pilocarpine induced much greater peak effects on both miosis and light reflex inhibition than from the aqueous solvent, and the time to peak effect was significantly prolonged.

Although blue-eyed subjects had a slightly greater degree of miosis and light reflex inhibition, these differences were not statistically significant. How-

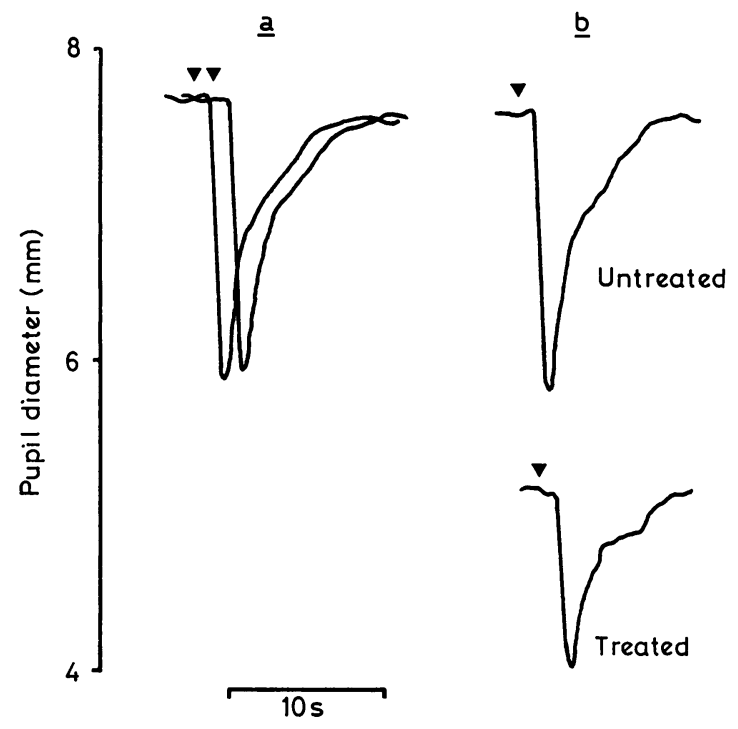

Fig. 1 Pupillary light reftexes (a) before, and (b) after application of aqueous pilocarpine to 1 eye. The responses of each eye are separated on the time axis for: convenience. A light flash $(\nabla)$ of $0.5 s$ duration was given to the untreated eye. In (a) the responses are equal whereas in (b) that of the treated eye is inhibited

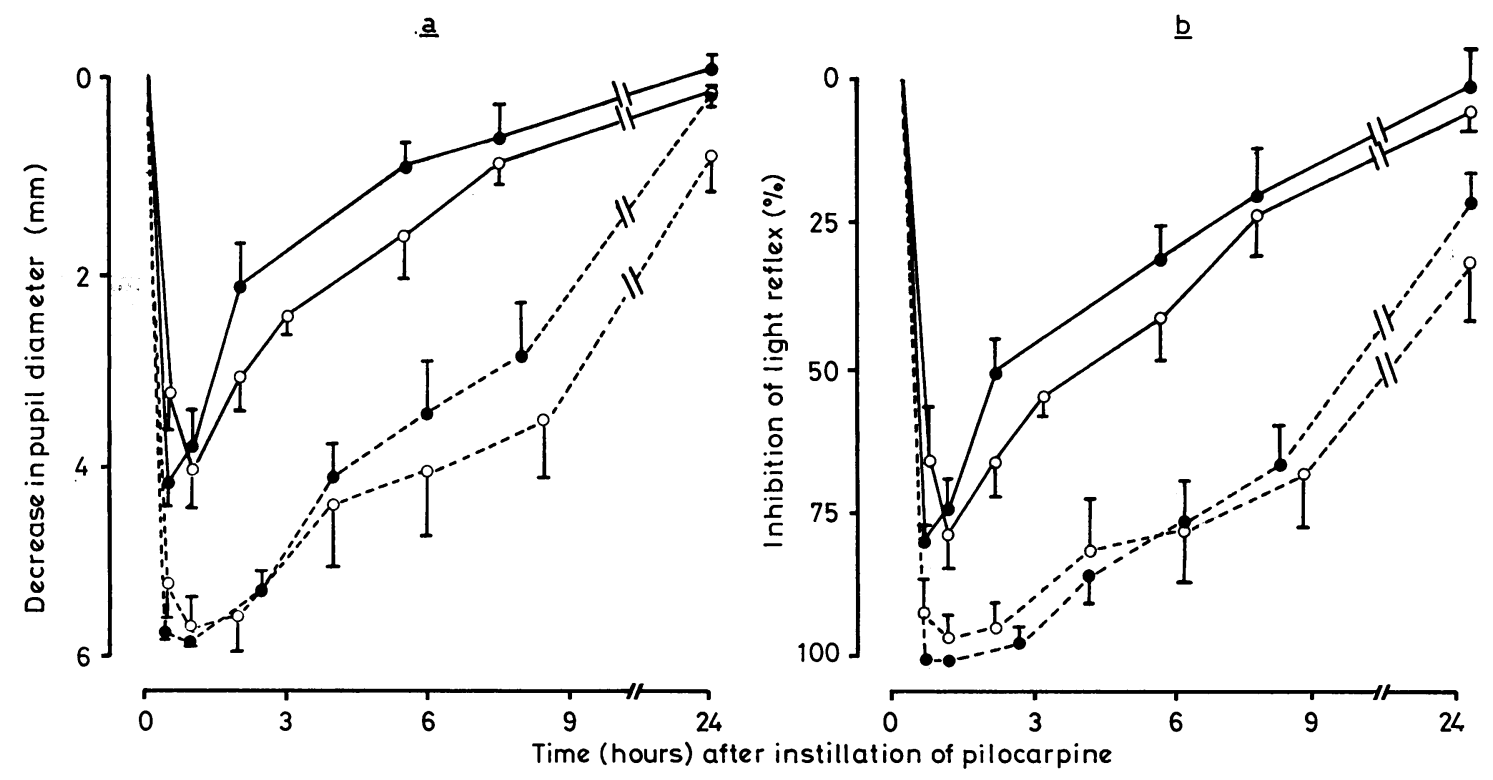

Fig. 2 The effect of equivalent doses of pilocarpine (see 'Methods') in aqueous (solid line) or oily (dotted line) solution on (a) diameter and (b) light reflex responses of the pupil in subjects with blue (O) and brown $(\bigcirc)$ eyes. For convenience of illustration only, each point represents the mean $( \pm S E M)$ effect at a time within 15 min either side of that indicated 
Table 1 Peak effects of $2 \%$ pilocarpine given in an oily and an aqueous vehicle. Results are expressed as the mean $\pm S E M$

\begin{tabular}{|c|c|c|c|c|c|c|}
\hline & Oily vehicle & & & Aqueous vehic & & \\
\hline & $\begin{array}{l}\text { Time to peak } \\
\text { (h) }\end{array}$ & $\begin{array}{l}\text { Miosis } \\
(\mathrm{mm})\end{array}$ & $\begin{array}{l}\text { Inhibition of } \\
\text { light reflex } \\
(\%)\end{array}$ & $\begin{array}{l}\text { Time to peak } \\
(h)\end{array}$ & $\begin{array}{l}\text { Miosis } \\
(\mathrm{mm})\end{array}$ & $\begin{array}{l}\text { Inhibition of } \\
\text { light reflex } \\
(\%)\end{array}$ \\
\hline $\begin{array}{l}\text { Blue-eyed subjects } \\
(n=6)\end{array}$ & $\begin{array}{r}0.93 \\
\pm 0.09\end{array}$ & $\begin{array}{r}5.91 \\
\pm 0.08\end{array}$ & $100 \cdot 0$ & $\begin{array}{r}0.58 \\
\pm 0.09\end{array}$ & $\begin{array}{r}4 \cdot 24 \\
\pm 0 \cdot 25\end{array}$ & $\begin{array}{l}\quad 80 \cdot 2 \\
\pm 3 \cdot 3\end{array}$ \\
\hline $\begin{array}{l}\text { Brown-eyed subjects } \\
(n=7)\end{array}$ & $\begin{array}{r}1.59 \\
\pm 0.23\end{array}$ & $\begin{array}{r}5.74 \\
\pm 0.35\end{array}$ & $\begin{array}{r}96.0 \\
\pm 4.0\end{array}$ & $\begin{array}{r}1 \cdot 15 \\
\pm 0 \cdot 11\end{array}$ & $\begin{array}{r}4.05 \\
\pm 0.44\end{array}$ & $\begin{aligned} & 77 \cdot 7 \\
\pm & 7 \cdot 0\end{aligned}$ \\
\hline $\begin{array}{l}\text { All subjects } \\
(n=13)\end{array}$ & $\begin{array}{r}1 \cdot 29 \\
\pm 0 \cdot 16\end{array}$ & $\begin{array}{r}5 \cdot 82 \\
\pm 0 \cdot 19\end{array}$ & $\begin{aligned} & 97 \cdot 8 \\
\pm & 2 \cdot 2\end{aligned}$ & $\begin{array}{r}0.89 \\
\pm 0.11\end{array}$ & $\begin{array}{r}4 \cdot 14 \\
\pm 0.26\end{array}$ & $\begin{aligned} & 78.8 \\
\pm & 3.9\end{aligned}$ \\
\hline
\end{tabular}

Table 2 The significance of the effect of drug solvent and eye colour on the response to pilocarpine

\begin{tabular}{lccc}
\hline & $\begin{array}{l}\text { Time to } \\
\text { peak } \\
(h)\end{array}$ & $\begin{array}{l}\text { Miosis } \\
(\mathrm{mm})\end{array}$ & $\begin{array}{l}\text { Light reflex } \\
\text { inhibition } \\
(\%)\end{array}$ \\
\hline $\begin{array}{l}\text { Mean solvent difference } \\
\text { (oil-aqueous) }\end{array}$ & 0.40 & 1.68 & 19.0 \\
SEM & 0.15 & 0.33 & 4.6 \\
P & $<0.02$ & $<0.001$ & $<0.001$ \\
$\begin{array}{l}\text { Mean colour difference } \\
\text { (brown-blue) }\end{array}$ & 0.61 & -0.18 & -3.3 \\
SEM & 0.15 & 0.33 & 4.6 \\
P & $<0.001$ & $\mathrm{NS}$ & $\mathrm{NS}$ \\
\hline NS $=$ Not significant & & & \\
\hline
\end{tabular}

ever, the brown-eyed people were significantly slower in reaching peak effects than the blue-eyed, and the total duration of drug effects was longer in the former group.

It was found that in all subjects miosis wore off more quickly than inhibition of the light reflex after pilocarpine treatment. This was particularly noticeable with the oily preparation (Fig. 2). For example, 24 hours after application of oily pilocarpine in the blue-eyed group the pupil diameter had returned to normal, whereas the light reflex response of the treated eye was still $20 \%$ smaller than that of the untreated eye.

\section{Discussion}

The present study has shown that application of pilocarpine in oil increases the degree and duration of pupillary drug effect. This finding confirms the observations of Borgmann and Wurster (1973), though in their study the quantities of drug instilled in the 2 vehicles were not strictly comparable. In the present study the prolongation of drug effect was such that every subject showed some evidence of drug action at 24 hours, indicating that oily pilocarpine is potentially a twice-daily treatment for glaucoma. Its use can be expected to improve levels of patient compliance, with ultimate benefit to control of the disorder. Preliminary studies on 6 patients with chronic simple glaucoma have shown the expected prolongation of the pressure-lowering effect. Pilocarpine Ocuserts, the drug-polymer combinations, were introduced for similar reasons, but an oily drop technique provides a more conventional and less expensive alternative.

There are 2 ways in which the action of pilocarpine may be increased and prolonged by giving the drug in oil. First, with aqueous drop therapy there is a rapid decrease in drug concentration in the conjunctival sac due to dilution in and turnover of the tear fluid (Chrai et al., 1974). Oily solvents on the other hand are less easily washed away, so that corneal contact time is prolonged (Hardberger et al., 1975). The finding that the time taken to reach peak effects was longer with the oily preparation is consistent with this concept. Secondly, the corneal penetration of pilocarpine, as with most ophthalmic drugs, is very low, since the tightly packed lipid cell membranes of the epithelium form a barrier to the entry of drug molecules which are ionised in solution. With aqueous pilocarpine about half is ionised at physiological $\mathrm{pH}$, whereas with an oily solvent all the drug is in its non-ionized form, which should cross the cornea more readily.

There were no reports of discomfort on instillation of the oily drops in contrast to the aqueous ones, which sometimes caused stinging. Owing to the large effects obtained with the oily drops, however, there were complaints of headaches and difficulty with accommodation which coincided with peak drug action. Such problems occur also when patients are first started on aqueous pilocarpine therapy, but tolerance is said to develop with time (Havener, 1970). The tight miosis which accompanied peak drug action was not troublesome to these healthy subjects, but it could provide visual problems for patients with glaucoma. Instillation of the drug preparation last thing at night would therefore be most appropriate. 
Previous studies on the effect of pilocarpine in subjects with differing eye colour indicated that dark-eyed people had significantly smaller miotic effects than light-eyed people (Barbee and Smith, 1957; Harris and Galin, 1971). However, in both these studies negroes were compared with caucasians, so that far larger differences in pigmentation were involved than in the present study using brown- and blue-eyed caucasians. This may explain why the difference in degrees of miosis was not large enough to be significant. There was, however, a clear difference in the time-course, with brown-eyed subjects reaching peak effects more slowly. This difference delayed the onset of recovery from the drug, which may explain why the total duration of miosis was longer in the brown-eyed subjects. It is as yet unclear whether drug binding by pigment (Lazare and Horlington, 1975; Salazar et al., 1976) or differences in the thickness of the anterior border layers of the iris (Emiru, 1971) are responsible for these well-known differences in the action of topical drugs on eyes of differing colour.

As the miotic effect of pilocarpine developed, the amplitude of the light reflex response was found to diminish concurrently. This can be explained in terms of drug receptor theory, which states that drug effect (decrease in pupillary diameter) increases hyperbolically, not linearly, with increasing drug concentration (of acetylcholine released during a light reflex or pilocarpine instilled). Thus, although the same amount of acetylcholine may be released during a reflex before or during pilocarpine action, in the latter case the acetylcholine is acting further up the hyperbolic dose-response curve. As the miotic effect of pilocarpine declined, it was found that the light reflex amplitude recovered, but it did so at a slower rate than the recovery of resting diameter-a finding noted before (Newsome and Loewenfeld, 1974). This cannot be explained simply by drugreceptor theory, and the reason for the 'after-effect' of pilocarpine on the light reflex has yet to be elucidated.
This work was supported by the Medical Research Council, the Prevention of Blindness Research Fund, and the Royal National Institute for the Blind.

\section{References}

Barbee, R. F., and Smith, W. O. (1957). A comparative study of mydriatic and cycloplegic agents. American Journal of Ophthalmology, 44, 617-622.

Borgmann, H., and Wurster, W. (1973). Der Einfluss unterschiedlicher Konzentrationen und Vehikel auf die Pilocarpin-Miosis. II. Unterschiedliche Vehikel. Klinische Monatsblätter für Augenheilkunde, 163, 51-56.

Chrai, S. S., Makoid, M. C., Eriksen, S. P., and Robinson, J. R. (1974). Drop size and initial dosing frequency problems of topically applied ophthalmic drugs. Journal of Pharmaceutical Science, 63, 333-338.

Emiru, V. P. (1971). Response to mydriatics in the African. British Journal of Ophthalmology, 55, 538-543.

Hardberger, R., Hanna, C., and Boyd, C. M. (1975). Effects of drug vehicles on ocular contact time. Archives of Ophthalmology, 93, 42-45.

Harris, L. S., and Galin, M. A. (1971). Effects of ocular pigmentation on hypotensive response to pilocarpine. American Journal of Ophthalmology, 72, 923-925.

Havener, W. H. (1970). In Ocular Pharmacology, 2nd edn., p. 233. C. V. Mosby Co: St. Louis.

Lazare, R., and Horlington, M. (1975). Pilocarpine levels in the eyes of rabbits following topical application. Experimental Eye Research, 21, 281-287.

Lowenstein, O., and Loewenfeld, I. E. (1958). Electronic pupillography. A new instrument and some clinical applications. Archives of Ophthalmology, 59, 352-362.

Newsome, D. A., and Loewenfeld, I. E. (1974). Pilocarpine re-examined: an old puzzle. Survey of Ophthalmology, 18, $399-424$.

Norn, M. S. (1964). Role of the vehicle in local treatment of the eye. Acta Ophthalmologica, 42, 727-734.

Salazar, M., Shimada, K., and Patil, P. N. (1976). Iris pigmentation and atropine mydriasis. Journal of Pharmacology and Experimental Therapeutics, 197, 79-88.

Snedecor, G. W., and Cochran, W. G. (1967). In Statistical Methods, 6th edn., p. 483. Iowa State University Press: Ames.

Swan, K. C., and White, N. G. (1942). Corneal permeability. I. Factors affecting penetration of drugs into the cornea. American Journal of Ophthalmology, 25, 1043-1058.

Vincent, P. (1971). Factors influencing patient noncompliance: a theoretical approach. Nursing Research, 20, 509-516. 